Is it not rather a malignant form of cynanche, (in which fibrinous exudation constitutes the first process, ) soon, under favouring circumstances, leading to the sloughing ulceration, \&c. \&c., so characteristic of this horrible malady?

I have seen three well-marked cases of the disease in the damp hills of India, and three in Europe, with the details of which I will, if you please, hereafter supply you, as also with the views which my limited experience has led me to form.

At present (and this is the object of my letter) let me simply mention what treatment I have found most successful in subduing the disease.

1. Chlorine injections along the floor of the nares, driven well against the back of the throat, and repeated three or four times a day. The injection is made according to the prescription given by Dr. Watson in his Lectures, vol. ii. p. 910, for a drink. I have used it for both purposes.

2. Topical application of nitrate of silver, in aqueous solutions of one drachm to an ounce; but I have observed far greater improvement from the chlorine injections, which have always given manifest relief.

3. It has been necessary to support the system almost from the commencement of the attack.

Out of six characteristic cases, one only has proved fatal.

I may add that, in my opinion, the disease is highly contagious. Hereafter I shall have to bring forward an interesting fact or two touching the tendency to "desquamative nephritis," which I have observed in diphthérite-a circumstance which would more certainly incline us to class it with the cynanche than with affections of the windpipe.

I enclose my card, and am, Sir, yours truly,

December, 1857 .

\section{THE BLOODLETTING CONTROVERSY.}

To the Editor of THE LANCET.

Sre,-With reference to the inflammation and bloodletting controversy, allow me to mention a case which may be interesting to your readers.

In the summer of 1855 , when in attendance on Turkish troops at Varna, I was called up one night to a tall, thin, cadaverous-looking man, who had been for weeks slowly convalescing from scurvy. I found him suffering from acute pleurisy, with violent pain, great dyspncea, and friction sound so loud all over the right side as to be heard without putting the ear to his chest. His pulse was rapid and hard, but small. As acute inflammatory affections are comparatively rare amongst the Turks, and as I had long wished to meet with a case like this to try the effect of bloodletting on their peculiar constitution, I immediately bled him to sixteen ounces, though his general health would have seemed to contra-indicate such a measure. The effect was instant relief of the symptoms. A dose of opium quieted him during the night. I auscultated him carefully in the morning, but could discover no abnormal sounds beyond a slight friction at the base of the lung. $\mathrm{He}$ took small doses of mercury for three or four days, no perceptible effusion took place, and, strange to say, he soon began to get fat and strong, and lost all trace of seurvy, which had obstinately clung to him for many weeks before the attack.

$I$ think no one can reasonably doubt, that if this man had not been bled at the critical moment, considerable effusion must have taken place. I am not an advocate of indiscriminate bleeding in these cases: I merely write to prove that pleurisy may be cut short by it, and that a considerable loss of blood, even in a debilitated subject, is not necessarily followed by such direful consequences as some would have us believe.

As that much-maligned place, Varna, has been lately mentioned in your columns, I may say, to prove that it is not such $a$ hotbed of disease as has been represented, that during the aummer of 1855 , there were no cases of epidemic diarrhcea, cholera, or fever of any kind in the Turkish tent-hospital on the liills north of the town, where the above incident occurred. The average number of patients was over 200 . I am, Sir, your obedient servant,

Richmond, December, 1857. $\quad$ S. D. BIRD, M.R.C.S., Late Surgeon, British Medical Staff, Ottoman Army.

\section{THE ROYAT INFIRMARY, EDINBURGH.}

$$
\text { To the Editor of THE LANCET. }
$$

SIR, - Knowing how ready you are at all times to have attention drawn to anomalous arrangements, in our medical schools, with regard to the teaching of any branch of medical education, I beo to direct your attention to the present position of the Professor of Surgery in this University.
The Professor, with a large class, has allotted to him two wards in the Royal Infirmary, containing between them fifteen patients. These wards are held by him during the winter session only, and are supposed to be sufficient to enable the Professor to present to his students cases explanatory of the views he may have enunciated in his lectures. Do the managers think that fifteen beds will enable the Professor to do justice to himself or to his students? Is it not preposterous that the Surgical Chair in the University of Edinburgh should have attached to it only two wards? Why should not the Professor have permanent wards? and why are the two wards he now has open only during the winter session? Let them, such as they are, be open summer and winter, or not at all. In every other medical school the teaching of surgery is held to be of importance; here, seemingly, it is not

Hoping that you will draw attention to this subject,

Edinburgh, Dec. 1857. I am, Sir, yours, \&c.,

M.D. EDIN.

\section{ON THE TREATMENT OF MENTAL DISEASES WITHOUT THE USE OF ALCOHOL.}

\section{To the Elitor of THE LANCeT.}

SIR,-On perusing your publication of Nov. 28th (p. 545), I confess to some surprise at the view Mr. Higginbottom takes concerning the medical treatment of the insane. He evidently looks upon the malady as inflammatory, instead of its cha. racter being one of pure debility. He says, "that the disuse of alcohol, in any form, would be attended with the most beneficial and happy results to all the inmates of Iunatic asylums." I cannot agree with him, that as excessive drinking occa. sionally produces insanity, so alcohol should be excluded entirely in the treatment of this disease; hence we should alto. gether refrain from administering opium and other poisons, as an over-dose destroys life, though it is curative in judicious quantities. In cases of acute mania, where we find all the concomitant symptoms of exhaustion, and in other forms of mental disorder, it will be found that stout, liberal diet, sedatives, and diffasible stimulants, are the most efficient means, and if taken early, rarely fail to restore or improve the mind. I firmly believe it would be highly prejudicial to debar insane persons the use of beer: stout, wine, and brandy are remedies more requisite to the insane sick than to those not so unkappily afflicted.

I am fully impressed with the conviction, that were $\mathrm{Mr}$. Higginbottom's method to be carried out, the per-centage of cures in county asylum would fall materially, as the inmates of such institutions are generally those worn down by anxiety, poverty, and all other causes tending to depress the vital powers, and to whom "barley-water, weak tea, pure water and milk, with light nutritious animal and vegetable food," would be fatal.

December, 1857 I am, Sir, yours obediently,

\section{THE LATE CASE OF ALLEGED MALPRACTICE IN MIDWIFERY. \\ To the Editor of THE LANCET.}

SIR,-I have just read the leading article in THE LANCET of the 21 st ult., on a case of alleged malpractice in midwifery. I remember a case of adherent placenta, so remarkably illustrative of the difficulties we sometimes meet with in these cases, and in certain circumstances so likely to injuriously affect the character of the medical man, that $I$ am induced to send you a few brief particulars of the case.

On the 30th of May, 1850, I was sent for by a brother practitioner to assist him in a case of retained placenta, which he had in vain attempted to remove. On introdueing the hand, the connexion with the uterus was found to be so intimate, that it was difficult to discover the line of separation between the two. In spite of the best endeavours to peel off the placenta, I was totally unable to separate the least portion of it, and with many fears for the future well-doing of the patient, I was obliged to desist, lest I should do her some great injury. A few days after I met my medical friend, and on inquiring the state of the patient, he told me that the placenta had been expelled on the third day, and the patient was making a good recovery.

Had the case terminated otherwise, I suppose it is more than probable that a coroner's jury would have summed up the verdict, as in the case of $\mathrm{Mr}$. Rolph, with severe reflections on the malpractice of the medical attendants. 